\title{
A Study on the $\mathrm{CO}_{2}$ Corrosion Behavior of P110 Steel in High- Density Cement
}

\author{
Huali Zhang ${ }^{1}$,Yufei Li $^{1}$, Shuliang Wang ${ }^{1,2, *}$, Jiaji Zhang ${ }^{2}$, Tuo Deng ${ }^{2}$, Xueni Zhang ${ }^{2}$, \\ Zhi Zhang ${ }^{3}$ \\ ${ }^{1}$ Gas Production Engineering Research Institute, PetroChina Southwest Oil and Gas Field Branch, \\ Chengdu, Sichuan 610017, China \\ ${ }^{2}$ School of New Energy and Materials, Southwest Petroleum University, Xindu Avenue 8\#, Sichuan \\ 610500, China \\ ${ }^{3}$ School of Petroleum Engineering, Southwest Petroleum University, Xindu Avenue 8\#, Sichuan \\ 610500, China \\ "E-mail: wsliang1465@126.com
}

Received: 1 October 2021 / Accepted: 8 December 2021 / Published: 5 January 2022

High-density cement slurry is commonly used for cementing deep and ultradeep wells. During service, corrosion problems at the interface between the cement and casing steel seriously affect the safety of oil and gas extraction. In this paper, a specimen of a high-density cement/casing steel system was prepared by using hematite powder as the weighting agent. The electrochemical properties and microstructure were investigated by electrochemical techniques, SEM, Raman spectroscopy and XPS. Samples were corroded in simulated formation water saturated with $\mathrm{CO}_{2}$ at $90{ }^{\circ} \mathrm{C}$ for $7-49$ days. The results show that with increasing immersion time, the corrosion rate of casing steel in cement gradually increases and the cement resistance first increases and then decreases. The pressure promotes the corrosion reaction; thus, the corrosion potential is more negative and the corrosion rate is higher. The corrosion product morphology on the surface of casing steel in cement is a distribution of cracks. The corrosion product is $\mathrm{FeCO}_{3}$, showing that mainly $\mathrm{CO}_{2}$ corrosion occurs. The microgap at the cement/casing steel interface is only $1.0 \mu \mathrm{m}$ and accompanied by $\mathrm{FeCO}_{3}$ production.

Keywords: High-density cement, P110 Steel, Cementing interface, $\mathrm{CO}_{2}$ corrosion, Electrochemistry

\section{FULL TEXT}

(C) 2022 The Authors. Published by ESG (www.electrochemsci.org). This article is an open access article distributed under the terms and conditions of the Creative Commons Attribution license (http://creativecommons.org/licenses/by/4.0/). 